\title{
Multimedia development to improve character analysis thinking skills through approaches
}

\author{
Arifin Arifin*) \\ STKIP 11 April Sumedang, Indonesia
}

\section{Article Info \\ Article history:}

Received Des $19^{\text {th }}, 2020$

Revised Jan $07^{\text {th }}, 2021$

Accepted Feb $23^{\text {rd }}, 2021$

\section{Keyword:}

Multimedia courseware

Value-based learning

\begin{abstract}
This research aims to develop interactive multimedia that can improve the quality of education, especially in strengthening students' character and personality, both holistically and comprehensively, according to the expectations of Indonesia's applicable curriculum. Qualitative methods are used in this study to get a complete picture to determine the developed multimedia response. The subjects of this study were one principal, two teachers, and five students. The instruments used in this study were in-depth interviews, observation, and documentation of the learning process using the developed multimedia. The results showed that students, in general, can use this multimedia in the learning process. There needs to be elaboration with teachers in different disciplines to present the material's depth according to the lessons. This research is recommended to all related parties who contribute to the development of students' quality following graduate standards' demands. In turn, it will produce a generation that is ready to enter a new era of knowledge, a better understanding of resources and factors that can affect both directly or indirectly, and it should be the basis for all related components and policymakers.
\end{abstract}

(C) 2021 The Authors. Published by Indonesian Institute for Counseling, Education and Therapy (IICET). This is an open access article under the CC BY license (https://creativecommons.org/licenses/by/4.0/)

\section{Corresponding Author:}

Arifin Arifin,

STKIP 11 April Sumedang

Email: arifin6368@gmail.com

\section{Introduction}

The emphasis upon rote memorization on repetitive skill drills in the public schools' curriculum has frequently meant that "problem-solving methodologies lie somewhere in the cracks and cobwebs of cluttered, unkempt classrooms." One educator described the typical curriculum in such schools as being "organized in lock-step fashion so that all children pass through the same sequences, ideally at the same ages, preferably on the same days (Linder, Powers-Costello, \& Stegelin, 2011). This lack of emphasis upon the ability to solve problems through an analytical thought process may mean that students are unprepared for the "complex nature of the twenty-first-century challenges" (Doerr \& Lesh, 2011). A pointed that analytical thinking is an effort to perceive a situation in detail, breaking up entities into their components, to compare and contrast, to find the root cause of a problem, and to find correlations between facts and situations.

Computer-supported collaborative (CSCL) has grown out of broader research into computer-supported collaborative work (CSCW) and collaborative learning. CSCW is defined as a computer-based network system that supports group work in a common task and provides a shared interface for groups to work with (Bravo, Duque, \& Gallardo, 2013; Schmidt \& Bannon, 2013; Wallace, Oji, \& Anslow, 2017). Collaborate learning is defined as groups working together for a common purpose. The differences between CSCW and CSCL are that CSCW tends to focus on communication techniques themselves, and CSCL focuses on what is being communicated; CSCW is used mainly in the business setting, CSCL is used in the educational setting; the purpose of CSCW is to facilitate group communication and productivity, and the purpose of 
CSCL is to scaffold or support students in learning together effectively (Bodemer \& Dehler, 2011; Järvelä \& Hadwin, 2013).

They both are based on the promise that a supported system can support and facilitate group processes and group dynamics in ways that are no possible face-to-face. Still, they are not designed to replace face-toface communication. CSCL systems are typically tailored for multiple learners working at the same workstation or across networked machines. These systems can support communicating ideas and information and providing feedback on problem-solving activities. The infrastructure is already in place in Indonesia's smart schools via the internetworking system using a main server as the communication hub. The interactive multimedia courseware is merely taking advantage of this provision. This study aims to see how the developed multimedia can systematically foster the value of thinking analytically, systematically, discipline, cooperation, and responsibility. In general, other research aims to see from the ability to think only. In contrast, other aspects are less observed (Krupat et al., 2011; Piaw, 2014); therefore, this study tries to discuss values that have not been available in previous studies.

\section{Method}

Qualitative research is natural, descriptive, and finding meaning from a phenomenon (Bryman, 2014; Kolb, 2012). The natural characteristic is defined that the study has a natural background as an actual data source. The researcher got involved in an educational setting in the junior high school. The purpose of involving in the setting was to consider the context. Various phenomena are viewed much better in the setting. For a qualitative researcher (Bryman, 2014), ignoring action, utterance, and gesture means losing an important meaning.

Data analysis employed in the research was inductive. The researcher did not find the data for proving or rejecting a hypothesis that had been formulated. Still, the researcher made an abstract when specific facts are collected and classified together. Inductive analysis is forms, themes, analytical categories from the data. The analysis searched for the variation from the existing data.

The meaning is developing an interactive multimedia courseware phenomena for Junior high school students in Sumedang after observation process, interacting with people, understanding the language, and interpreting their world as the research setting. Qualitative research (Bryman, 2014) uses large lenses, finding the relationship patterns between the previous concepts. In the last stage, the researcher attempts to find the educational model of law awareness and internal and external influencing factors of students develop interactive multimedia courseware at Junior high school in Sumedang as a research setting.

To focus on studying student's analytical thinking at Junior high school in Sumedang, the researcher investigated the teacher qualification, plan, approach and teaching method, and educational evaluation. The research used a holistic point of view and analytical thinking as a central foundation. The foundation was employed to obtain a clear, deep, and comprehensive study and identify and relate the factors and decide students' determining factors.

The holistic approach in the study, which was based on the theory of thinking skills via the school-based network system foundation, included 2 (two) studies: first, students in Junior high school in Sumedang, as a development interactive multimedia courseware for students in Junior high in Sumedang as a focused study and second, other studies including teacher qualification, plan, approach and method, and educational evaluation appearing "a good student character in Junior high school in Sumedang" which are based on life skills: self-awareness, thinking skills, communication, cooperation, and vocational skills.

\section{Results and Discussion}

Generally, the research aims to describe, analyze, and find the model of student character education at Junior school in Sumedang. Specifically, the research is aimed at finding out, describing, analyzing, and discovering: 1) the appropriate model of developing interactive multimedia courseware for Junior high school students in Sumedang; 2) the development of interactive multimedia courseware is obtained from a teacher qualification, plan, and teaching method, and educational evaluation in student's characters at Junior high school in Sumedang; 3) the supporting and obstacle factors in the character educational process in Junior high school in Sumedang are recognized after the analytical process towards the existing educational model; 4) the development of student character education is clarified from a teacher qualification, plan, approach and teaching method, and evaluation system;5) an existing and predicted 
strength, weakness, opportunity, and threat in implementing student develop interactive multimedia courseware at Junior high school in Sumedang are evaluated.

It is found that there are internal and external factors influencing the development of interactive multimedia courseware from Elementary level to Junior high level from the educational process conducted in Sumedang, they are: First, a teacher qualification should also be served as a role model, understand student logical aspects, and have close relationships with Skill to support a student interactive multimedia courseware in Sumedang. Second, the teaching plan uses two mixed models: top-down and bottom-up. It is used to bridge the gap between the expected teaching program and reality in society. Interactive multimedia courseware gives space to improve school management, developing an appropriate teaching method for a formal school. Simultaneously, a teaching method based on the certain condition by using a bottom-up approach should also be developed. Third, teaching approach and method combining analytical thinking capabilities of the student from the point of view of inquiry-based learning approach model will constructively stand along as a future teaching model for students by doing the following approach and method: a) emphasizing: (1) good model, (2) conditioning and drilling, (3) creating a comfortable situation with the situation, system, infrastructure, work and achievement, art and culture, and (4) discipline, encourage the improvement of character educational; b) teaching approach through an interaction happened in students (Junior high) with different punishment influencing each other. c) Individual and group approaches should be applied to both female and male students.

Developing intrinsic motivation among learners is key to activating knowledge (de Barba, Kennedy, \& Ainley, 2016; Larson \& Rusk, 2011). Philip, Way, Garcia, Schuler-Brown, \& Navarro (2013) contended that learning tasks must be "intrinsically related to an exciting or at least coherent goal rather than for some extrinsic reason getting a good grade or pleasing the teacher. "When learning is valued for personal reason, it is more likely to be activated in multiple settings (Markram, 2012). further, when the learner values knowledge, teaching methods such as modeling, coaching, and scaffolding are enhanced. Teachers who exploit and foster collaborative among learners will greatly enhance advanced cognitive skills-learning through collaborative problem solving is both a powerful motivator and a powerful mechanism for extending learning resources (Kessler, Bikowski, \& Boggs, 2012).

The inquiry approach is a useful model for developing thinking skills within the context of real situations (Artigue \& Blomhøj, 2013; Yilmaz, Tekkaya, \& Sungur, 2011). The inquiry approach attempts to help students identify and learn specific strategies for handling data of research problems. It is therefore a powerful tool for initiating students into the types of thinking required in the various disciplines. A carefully designed inquiry assignment presents students with challenging thinking situations, factual data to manipulate, and many opportunities to discuss the problem situation. Students are coached through important modes of thought/discourse, such as careful observation and analysis. This focused attention is very effective in increasing the range of thinking strategies students can apply to problem-solving situations.

Interactivity in thinking skills courseware amounts to designing computer-based activities that mimics the mental process which cognitively engage the learner to think about the ideas are generated and its relevance to the problem at hand as a result of thinking analytically in a broad perspective (Chen \& Tsai, 2012; Essel, Osei-poku, \& Opoku-asare, 2016). The process of real-time feedbacks and hints in the form of 'dialogues' provide the backbone for a verbal mapping network, which encourages reflective thinking and a deeper understanding of the situation at hand (Chin, Hong, Huang, Shen, \& Lin, 2016) As such, interactivity in multimedia provides for reflection and supports collaborative learning in an open learning environment.

\section{Conclusion}

The advent of the courseware only provides an alternative to conventional methods in training for analytical thinking skills. It is not based on subject-matter domain knowledge and thus will not interfere with academic class proceedings. It is student-oriented and at the students' preferred learning pace while making optimum use of the computer intra-network system installed in smart schools for collaborative learning purposes. It remains to be seen whether students can successfully transfer the strategic thinking process into the subject matter or will they ever have a chance to do so.

\section{References}

Artigue, M., \& Blomhøj, M. (2013). Conceptualizing inquiry-based education in mathematics. ZDM International Journal on Mathematics Education, 45(6), 797-810. https://doi.org/10.1007/s11858-013- 
0506-6

Bodemer, D., \& Dehler, J. (2011). Group awareness in CSCL environments. Computers in Human Behavior, 27(3), 1043-1045. https://doi.org/10.1016/j.chb.2010.07.014

Bravo, C., Duque, R., \& Gallardo, J. (2013). A groupware system to support collaborative programming: Design and experiences. Journal of Systems and Software, 86(7), 1759-1771. https://doi.org/10.1016/j.jss.2012.08.039

Bryman, A. (2014). June 1989 and beyond: Julia Brannen's contribution to mixed methods research. International Journal of Social Research Methodology, 17(2), 121-131. https://doi.org/10.1080/13645579.2014.892653

Chen, C. M., \& Tsai, Y. N. (2012). Interactive augmented reality system for enhancing library instruction in elementary schools. Computers and Education, 59(2), 638-652. https://doi.org/10.1016/j.compedu.2012.03.001

Chin, K. Y., Hong, Z. W., Huang, Y. M., Shen, W. W., \& Lin, J. M. (2016). Courseware development with animated pedagogical agents in learning system to improve learning motivation. Interactive Learning Environments, 24(3), 360-381. https://doi.org/10.1080/10494820.2013.851089

de Barba, P. G., Kennedy, G. E., \& Ainley, M. D. (2016). The role of students' motivation and participation in predicting performance in a MOOC. Journal of Computer Assisted Learning, 32(3), 218-231. https://doi.org/10.1111/jcal.12130

Doerr, H. M., \& Lesh, R. (2011). Models and Modelling Perspectives on Teaching and Learning Mathematics in the Twenty-First Century. 247-268. https://doi.org/10.1007/978-94-007-0910-2_26

Essel, H. B., Osei-poku, P., \& Opoku-asare, N. A. (2016). Self-Paced Interactive Multimedia Courseware: A Learning Support Resource for Enhancing Electronic Theses and Dissertations Development. Journal of Education and Practice, 7(12), 74-84.

Järvelä, S., \& Hadwin, A. F. (2013). New Frontiers: Regulating Learning in CSCL. Educational Psychologist, 48(1), 25-39. https://doi.org/10.1080/00461520.2012.748006

Kessler, G., Bikowski, D., \& Boggs, J. (2012). Collaborative writing among second language learners in academic web-based projects. Language Learning and Technology, 16(1), 91-109.

Kolb, S. M. (2012). Grounded Theory and the Constant Comparative Method : Valid Research Strategies for Educators. Journal of Emerging Trends in Educational Research and Policy Studies, 3(1), 83-86. Retrieved from http://jeteraps.scholarlinkresearch.com/articles/Grounded Theory and the Constant Comparative Method.pdf

Krupat, E., Sprague, J. M., Wolpaw, D., Haidet, P., Hatem, D., \& O’Brien, B. (2011). Thinking critically about critical thinking: Ability, disposition or both? Medical Education, 45(6), 625-635. https://doi.org/10.1111/j.1365-2923.2010.03910.x

Larson, R. W., \& Rusk, N. (2011). Intrinsic Motivation and Positive Development. In Advances in Child Development and Behavior (1st ed., Vol. 41). https://doi.org/10.1016/B978-0-12-386492-5.00005-1

Linder, S. M., Powers-Costello, B., \& Stegelin, D. A. (2011). Mathematics in Early Childhood: ResearchBased Rationale and Practical Strategies. Early Childhood Education Journal, 39(1), $29-37$. https://doi.org/10.1007/s10643-010-0437-6

Markram, B. H. (2012). transform neuroscience and medicine and reveal new ways of making more powerful computers It's time to change the way we study the brain. 306(June), 50-55.

Philip, T. M., Way, W., Garcia, A. D., Schuler-Brown, S., \& Navarro, O. (2013). When educators attempt to make 'community' a part of classroom learning: Thedangers of (mis)appropriating students' communities into schools. Teaching and Teacher Education, 34, 174-183. https://doi.org/10.1016/j.tate.2013.04.011

Piaw, C. Y. (2014). Effects of Gender and Thinking Style on Student's Creative Thinking Ability. Procedia Social and Behavioral Sciences, 116, 5135-5139. https://doi.org/10.1016/j.sbspro.2014.01.1087

Schmidt, K., \& Bannon, L. (2013). Constructing CSCW: The first quarter century. Computer Supported Cooperative Work: CSCW: An International Journal, 22(4-6), 345-372. https://doi.org/10.1007/s10606013-9193-7

Wallace, J. R., Oji, S., \& Anslow, C. (2017). Technologies, Methods, and Values. Proceedings of the ACM on Human-Computer Interaction, 1(CSCW), 1-18. https://doi.org/10.1145/3134741

Yilmaz, D., Tekkaya, C., \& Sungur, S. (2011). The Comparative effects of prediction/discussion-based learning cycle, conceptual change text, and traditional instructions on student understanding of genetics. International Journal of Science Education, 33(5), 607-628. https://doi.org/10.1080/09500691003657758 